\title{
Analisis Struktur Jembatan Sungai Kampung Tengah Kecamatan Pelayangan Kota Jambi
}

\author{
${ }^{1}$ Suhendra, ${ }^{2}$ M. Nuklirullah, ${ }^{3}$ Ilham Fadel Muhammad \\ ${ }^{1,2}$ Dosen Fakultas Teknik Sipil Universitas Batanghari Jambi \\ ${ }^{3}$ Mahasiswa Teknik Sipil Universitas Batanghari Jambi \\ Email : suhendra_domas@yahoo.com
}

\begin{abstract}
Abstrak
Jembatan Sungai Kampung Tengah merupakan jembatan yang berada pada area lahan persawahan yang memiliki panjang jembatan 300 meter dengan panjang bentang 10 meter dan lebar 3 meter, jembatan yang difungsikan untuk perlintasan kendaraan maksimum gerobak motor roda 3 yang mengangkut hasil pertanian. Analisis ini bertujuan mendesain ulang suatu jembatan yang ada di Sungai Kampung Tengah Kecamatan Pelayangan Kota Jambi dengan menggunakan peraturan pembebanan jembatan terbaru yaitu SNI 1725:2016 tentang Pembebanan Untuk Jembatan, dan untuk perhitungan konstruksi beton menggunakan peraturan Manual Konstruksi dan Bangunan No.009/BM/2008 tentang Perencanaan Struktur Beton Bertulang untuk Jembatan. Dari data exixting jembatan tersebut menggunakan 3 buah gelagar memanjang dengan panjang $10 \mathrm{~m}$, berdasarkan analisa perhitungan jembatan dengan menggunakan peraturan tersebut didapatkan jembatan tersebut dapat menggunakan 2 gelagar memanjang pada jembatan tersebut, yang ini juga dapat berakibat pada pengurangan beban dari struktur atas terhadap struktur bawah jembatan tersebut.
\end{abstract}

Kata Kunci : Analisa Beban, Analisa Struktur, Gambar Desain.

\section{PENDAHULUAN}

Jembatan merupakan prasarana utama dalam menghubungkan 2 (dua) bagian yang terputus yang diakibatkan suatu rintangan yang tidak bisanya dibungun jalan secara konvensional, namun juga jembatan bukan hanya untuk menyeberangkan orang atau pun kendaraan yang selama ini kita ketahuin akan tetapi kebutuhan jembatan untuk menghubungkan saluran perpipaan air, minyak, maupun gas, dan ada pula yang menghubungkan suatu aliran air yang menyerupai sungai seperti yang ada di negara-negara Eropa

Pada jembatan tersebut di lihat dari segi penggunaanya, jembatan tersebut diperuntukan untuk beban kendaraan ringan seperti motor atau pun grobak motor yang hanya memliki muatan $1000 \mathrm{Kg}$, tetapi mengunakan hingga 3 gelagar yang dapat memikul beban lebih besar, maka dari itu perlunya melakukan perhitungan ulang sehingga mengetahui keefesiensinya jembatan tersebut.

Dalam hal ini analisis pada jembatan Sei. Kampung Tengah yang berada pada Kecamatan Pelayangan itu sangat diperlukan untuk menjadi bahan evaluasi dan kajian bersama, yang dimana kondisi alam pada daerah tersebut merupakan area persawahan yang memiliki pintu air untuk jaringan irigasi. Jembatan kelas $\mathrm{C}$ yang bertujuan untuk memudahkan pengangkutan hasil tani pada area tersebut.

\section{Landasan Teori}

Berdasarkan UU 38 Tahun 2004 bahwa jalan dan jembatan sebagai bagian dari sistem transportasi nasional mempunyai peranan penting terutama dalam mendukung bidang ekonomi, sosial dan budaya serta lingkungan yang dikembangkan melalui pendekatan pengembangan wilayah agar tercapai keSeimbangan dan pemerataan pembangunan antar daerah.

Jembatan adalah suatu konstruksi yang gunanya untuk meneruskan jalan melelui rintangan yang berada lebih rendah. Rintangan ini biasanya jalan lain (jalan air atau jalan lalu lintas biasa). Yang dimaksud jembatan beton adalah bangunan jembatan yang strukturnya 
mengunakan beton bertulang khususnya pada bangunan atas (upper structrure) (Asiyanto,2005). Dan menuru Asiyanto dalam bukunya berjudul Metode Konstruksi Jembatan Beton, secara umum fungsi jembatan apapun sama, yaitu bangunan yang menghubungkan secara fisik untuk keperluan pelayanan transportasi dari tempat unjung satu ke ujung lainnya, yang terhalang oleh kondisi alam atau bangunan lain.

Dalam menganalisis jembatan menggunakan SNI 1725:2016 tentang Pembebanan Untuk Jembatan. Standar ini menetapkan ketentuan pembebanan dan aksi - aksi lainnya yang akan digunakan dalam perencanaan jembatan jalan raya termasuk jembatan pejalan kaki dan bangunan - bangunan sekunder yang terkait dengan jembatan. Butir - butir tersebut di atas harus digunakan untuk perencanaan seluruh jembatan termasuk jembatan bentang panjang dengan bentang utama $\geq 200 \mathrm{~m}$.

Manual Konstruksi dan Bangunan No.009/BM/2008 tentang Perencanaan Struktur Beton Bertulang untuk Jembatan tahun 2008, dapat digunakan untuk perencanaan jembatan jalan raya maupun jembatan pejalan kaki, dengan menggunakan beton normal (berat isi \pm $2400 \mathrm{~kg} / \mathrm{m} 3$, fc'antara $20 \mathrm{MPa}$ s.d $60 \mathrm{MPa}$ ), beton ringan ( berat isi $\pm 2000 \mathrm{~kg} / \mathrm{m} 3$, fc'antara $20 \mathrm{MPa}$ s.d $40 \mathrm{Mpa}$ ) dan beton bermutu tinggi ( $\left.\mathrm{fc}^{\prime}>60 \mathrm{Mpa}\right)$.

Pondasi diperlukan agar konstruksi dapat aman terhadap geser dan ketidakstabilitasan tanah, pemilihan pondasi disesuaikan dengan kondisi dan keadaan tanah. Pada Jembatan ini jenis pondasi yang dipilih adalah pondasi tiang pancang dengan diameter $300 \mathrm{~mm}$.

Beban-beban yang diterima oleh pondasi tiang pancang adalah:

a. Beban vertikal

b. Berat sendiri pondasi

c. Stabilitas pondasi tiang pancang

\section{METODE}

Metode penelitian ini dilakukan menggunakan sebagian desain lama jembatan berupa ukuran penampang yang ada. Penelitian ini bertujuan untuk merencakan ulang jembatan sehingga mendapatkan keefesienan dari jembatan tersebut dengan beban yang kecil. Penerencanaan ini menggunakan Peraturan Manual Konstruksi dan Bangunan No. 009/BM/2008 Perencanaan Struktur Beton Bertulang untuk Jembatan dan pada pembebanan menggunakan peraturan SNI 1725:2016 Pembebanan untuk Jembatan. Untuk mencapai tujuan tujuan tersebut langkah pertama memahamin keadaan jembatan secara fisik maupun gambar rencana sebelumnya, lanjut dilakukan analisis beban pada jembatan yang akan di rencanakan ulang, dan setelah didapat yang masuk perhitungan struktur jembatan tersebut, dan perhitungan struktur meliputin analisis struktur jembatan yaitu tiang sandaran, plat lantai jembatan, gelagar memanjang, balok diafragma, dan juga struktur bawah jembatan yaitu pondasi tiang pancang, dan abutment trestle.

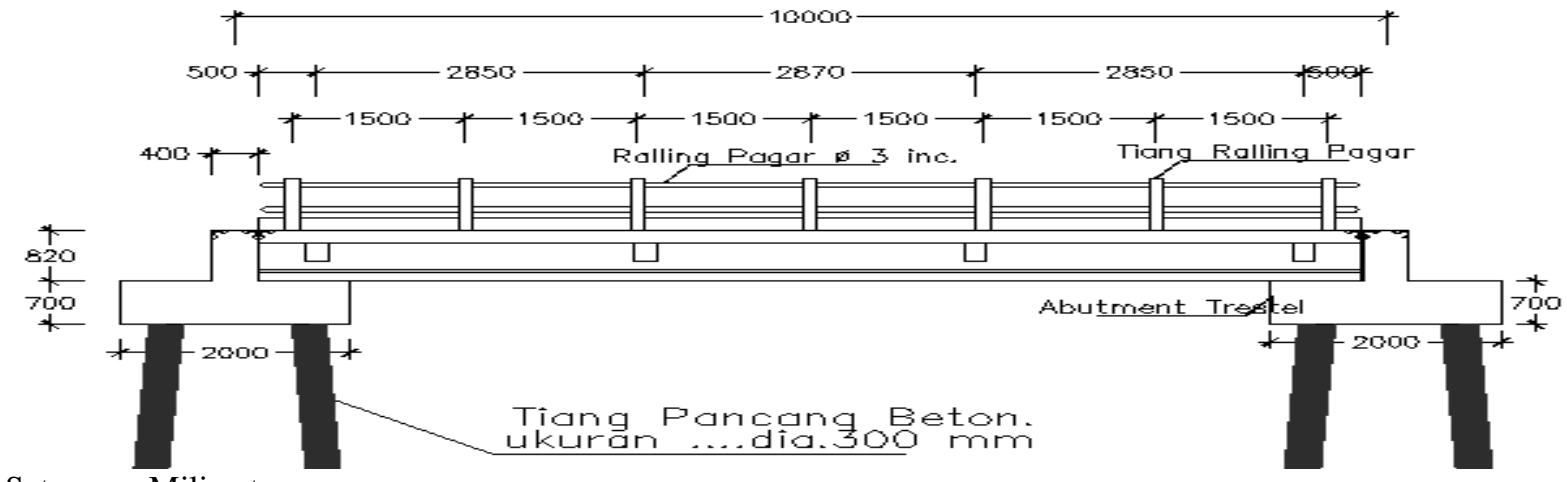

Satuan : Milimeter

Sumber: Analisa Perhitungan (2019)

Gambar 1: Potongan Memanjang Jembatan 


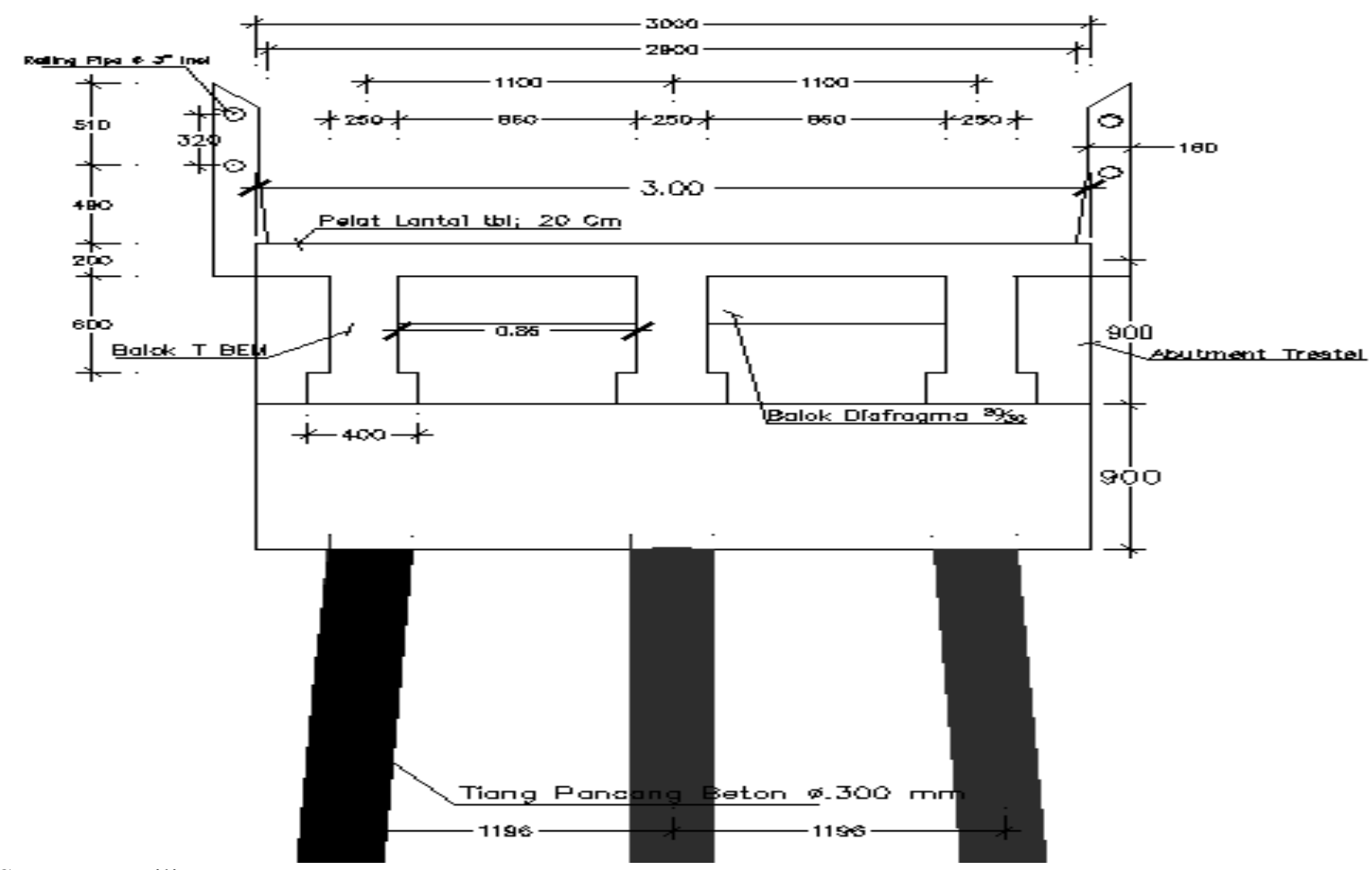

Satuan : Milimeter

Sumber: Analisa Perhitungan (2019)

Gambar 2: Potongan Melintang Jembatan

\section{HASIL}

\section{Sandaran}

Diproleh data perencanaan $\mathrm{b}=120 \mathrm{~mm}, \mathrm{~h}=160 \mathrm{~mm}$, selimut beton $=40 \mathrm{~mm}, \mathrm{~L}=$ $1500 \mathrm{~mm}$ (jarak antara tiang sandaran), fy $(\mathrm{BjTP} 30)=240 \mathrm{MPa}, \mathrm{f}^{\prime} \mathrm{c}=14,525 \mathrm{MPa}=\mathrm{K} 175, \varnothing$ tulangan $=12 \mathrm{~mm}$, Øsengkang $=8 \mathrm{~mm}, \phi$ (faktor reduksi) $=0,8($ RSNI T-12-2004, pasal 4,5,2), $\mathrm{d}=\mathrm{h}$-cc-0,5 Øtulangan $-\emptyset$ sengkang $=110 \mathrm{~mm}$. Pembebanan $\mathrm{P}=150 \mathrm{~kg}, \mathrm{M}=150 \mathrm{x}$ $0,82=123 \mathrm{~kg}, \mathrm{~m}=1,23 \times 10^{6} \mathrm{~N}, \mathrm{~mm}$

Penulangan tiang sandaran tulangan lentur dipakai tulangan $\varnothing 12$ dengan luas penampang $\left(\mathrm{A}=113,097 \mathrm{~mm}^{2}\right)$ Jumlah tulangan $=2$. Tulangan Geser $\mathrm{Vu}=1500 \mathrm{~N}$ dipakai tulangan $\varnothing 8 \mathrm{~mm} \mathrm{Av}=50,26 \mathrm{~mm}^{2}$ jarak tulangan sengkang yang diperlukan $200 \mathrm{~mm}$

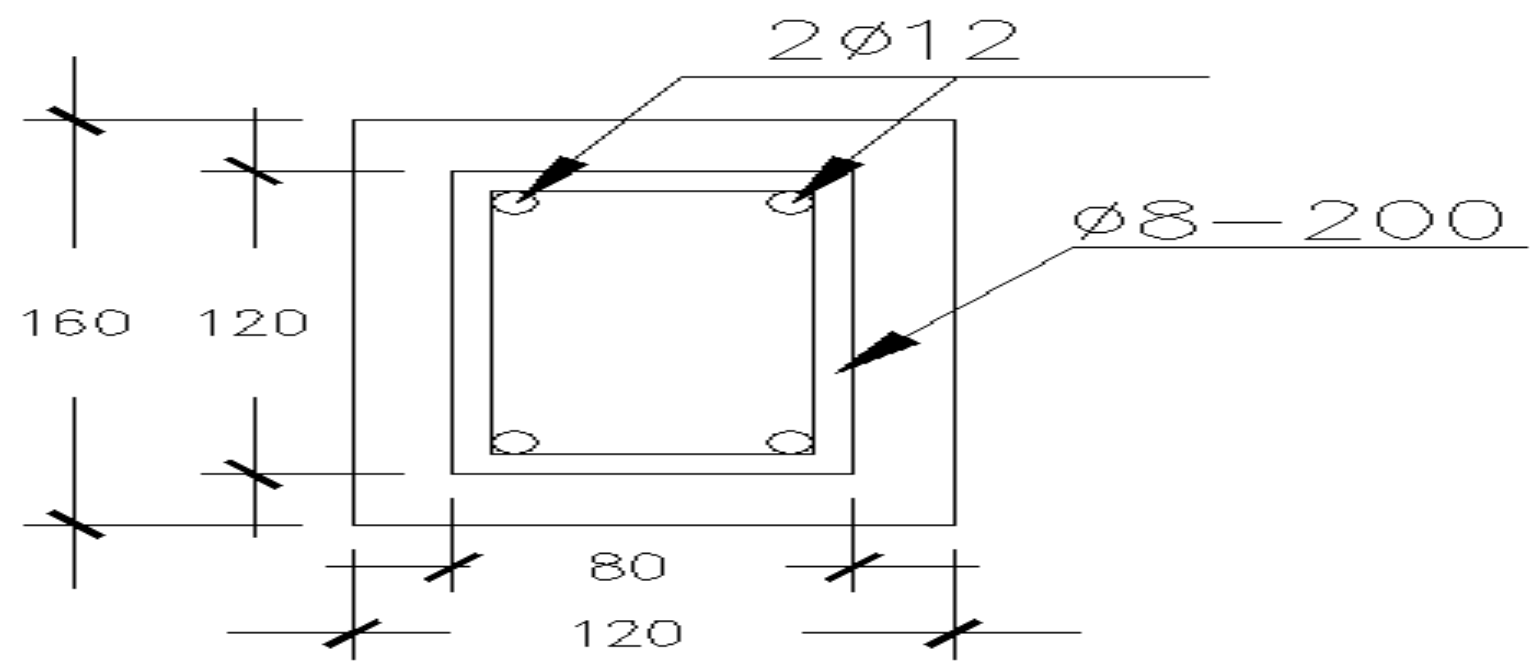

Satuan : Milimeter

Sumber: Analisa Perhitungan (2019)

Gambar 3: Penulangan Tiang Sandaran 


\section{Plat Lantai Jembatan}

Data Perencanaan $\mathrm{h}=20 \mathrm{~cm}$ (tebal plat lantai), th $=3 \mathrm{~cm}$ (tebal air hujan), selimut beton $=4 \mathrm{~cm}, \mathrm{Lx}=2,2 \mathrm{~m}, \mathrm{Ly}=10 \mathrm{~m}, \mathrm{fy}=295 \mathrm{MPa}, \mathrm{fc}=24,9 \mathrm{MPa}, \mathrm{BJ}$ Beton $=2400 \mathrm{~kg} / \mathrm{m}^{3}$, BJ Air Hujan $=1000 \mathrm{~kg} / \mathrm{m}^{3}$

Tabel 1. Kombinasi Beban pada Plat Lantai

\begin{tabular}{llrrrrr}
\hline No & Jenis Beban & Faktor Beban & M, Tumpuan & M, Lapangan & (MuTx) & (MuLx) \\
\hline 1 & Beban Sendiri (MS) & 1,3 & 193,7 & 96,8 & 251,68 & 125,84 \\
2 & Beban Mati Tambahan (MA) & 2 & 12,1 & 1,01 & 24,2 & 12,100 \\
3 & Beban Truk "T" (TT) & 1,8 & 300,98 & 115,02 & 541,759 & 207,031 \\
\hline \multicolumn{2}{c}{ Total Momen Ultimit Plat Lantai (Mu) $(\mathrm{kg}, \mathrm{m})$} & & 817,639 & 344,971 \\
\hline
\end{tabular}

Sumber: Analisa Perhitungan (2019)

Penulangan Lentur Positif dipakai tulangan D12 dengan luas penampang ( $\mathrm{A}=113,1$ $\mathrm{mm}^{2}$ ), Jarak tulangan yang diperlukan $150 \mathrm{~mm}$. Tulangan susut/ bagi arah memanjang diambil $30 \%<\frac{110}{\sqrt{L x}}<67 \%$ tulangan pokok (Manual Konstruksi dan Bangunan No,009/BM/2008, pasal 7,1,3), dipakai tulangan bagi/ susut D12 - 200. Penulangan Lentur Negatif $\mathrm{Mn}=\mathrm{MLy} / \phi=817,639 / 0,8=16,35 \times 10^{6} \mathrm{~N}, \mathrm{~mm}$, dipakai tulangan $\varnothing 12$ dengan luas penampang $\left(\mathrm{A}=113,1 \mathrm{~mm}^{2}\right)$, Jarak tulangan yang diperlukan $150 \mathrm{~mm}$. Tulangan susut/ bagi arah memanjang diambil 30\% $<\frac{110}{\sqrt{L x}}<67 \%$ tulangan pokok (Manual Konstruksi dan Bangunan No,009/BM/2008, pasal 7,1,3) dipakai tulangan bagi/ susut D12-200mm.

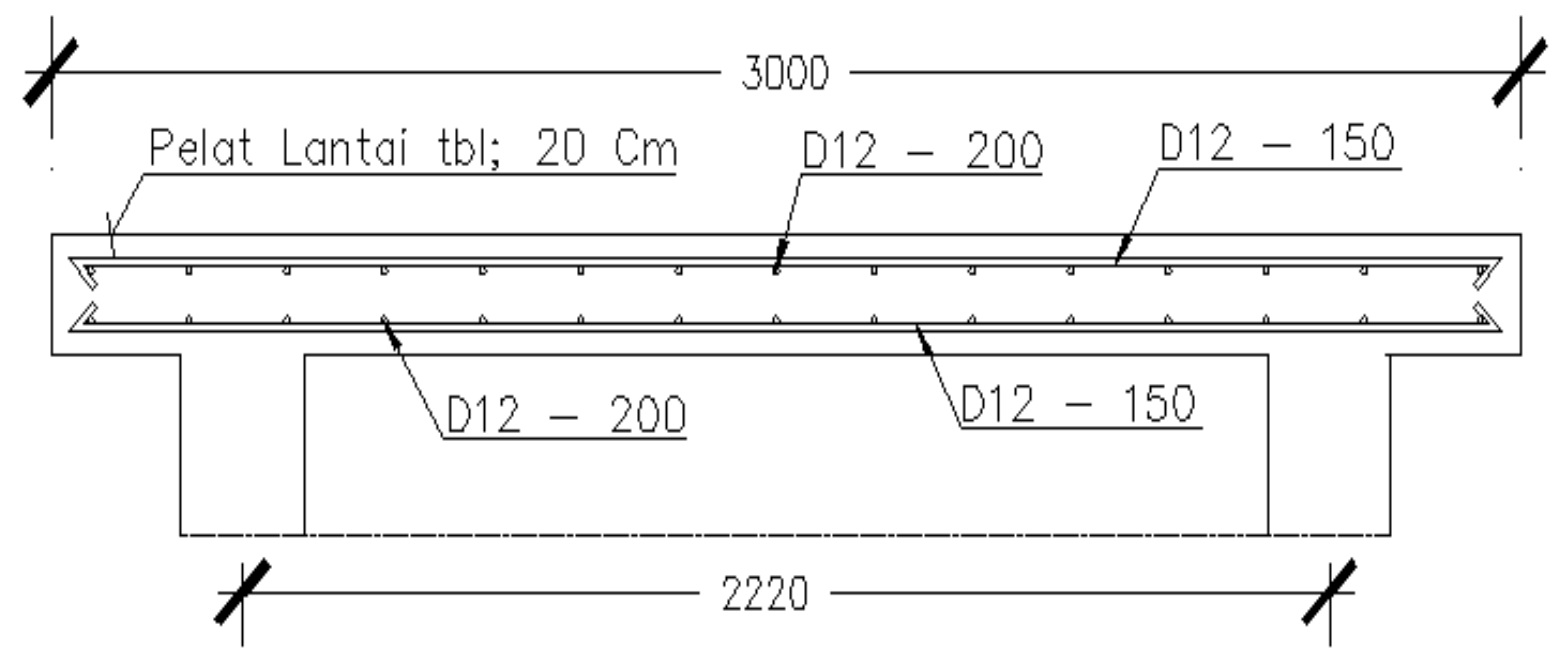

Satuan : Milimeter

Sumber: Analisa Perhitungan (2019)

\section{Gambar 4: Penulangan Plat Lantai}

\section{Gelagar Memanjang Jembatan}

Data Perencanaan Panjang bentang $(\mathrm{L})=10 \mathrm{~m}$, jumlah bentang $(\mathrm{n})=2$, tebal air hujan $=3 \mathrm{~cm}$, Lebar Jembatan $=3 \mathrm{~m}$, fy $=295 \mathrm{MPa}, \mathrm{fc}=24,9 \mathrm{MPa}$, BJ Beton $=2400 \mathrm{~kg} / \mathrm{m}^{3}$, BJ Air Hujan $=1000 \mathrm{~kg} / \mathrm{m}^{3}$

Tabel 2. Kombinasi Beban pada Gelagar

\begin{tabular}{|c|c|c|c|c|c|c|}
\hline No & Jenis Beban & Faktor Beban & $\mathrm{M}, \operatorname{Max}(\mathrm{Kg}, \mathrm{m})$ & $\mathrm{V}, \operatorname{Max}(\mathrm{Kg})$ & $\mathrm{Mu}(\mathrm{Kg}, \mathrm{m})$ & $\mathrm{Vu}(\mathrm{Kg})$ \\
\hline 1 & Beban Sendiri (MS) & 1,3 & 15359,04 & 6204,96 & 19966,752 & 8066,448 \\
\hline 2 & Beban Mati Tambahan (MA) & 2 & 562,5 & 225 & 1125 & 450 \\
\hline 3 & Beban Truk "T" (TT) & 1,8 & 400725 & 11145 & 73305 & 20061 \\
\hline \multicolumn{5}{|c|}{ Total Momen Ultimit Plat Lantai (Mu) (kg,m) } & 94396,752 & 28577,45 \\
\hline
\end{tabular}

Sumber: Analisa Perhitungan (2019) 
Penulangan Lentur $\mathrm{Mu}=94396,752 \mathrm{Kg}, \mathrm{m}, \mathrm{bw}=250 \mathrm{~mm}, \mathrm{~b}=400 \mathrm{~mm}, \mathrm{hf}=200 \mathrm{~mm}$, $\mathrm{h}=1000 \mathrm{~mm}, \mathrm{cc}=40 \mathrm{~mm}, \phi($ faktor reduksi $)=0,8($ RSNI T-12-2004, pasal 4,5,2), D tulangan $=22 \mathrm{~mm}, \varnothing$ sengkang $=12 \mathrm{~mm}, \mathrm{~d}=937 \mathrm{~mm}, \mathrm{Mn}=1,18 \times 10^{9} \mathrm{~N}, \mathrm{~mm}$, dipakai tulangan D22 dengan luas penampang $\left(A=380,13 \mathrm{~mm}^{2}\right)$, Jumlah tulangan 13, Untuk menjamin agar gelagar bersifat daktail, maka tulangan tekan diambil 30\% tulangan tarik, sehingga As' = 1482,578 $\mathrm{mm}^{2}$, Jumlah tulangan 4. Penulangan Geser $\mathrm{Vu}=285774,48 \mathrm{~N}, \phi$ (faktor reduksi) $=0,7($ RSNI T-12-2004, pasal 4,5,2), dipakai tulangan sengkang $\varnothing 12 \mathrm{~mm} \mathrm{Av}$ $=113,097 \mathrm{~mm}^{2}$, Jarak tulangan sengkang yang diperlukan $200 \mathrm{~mm}$. Pada badan gelagar dipasang tulangan susut minimal dengan rasio tulangan $r s h=0,001$, dipakai tulangan susut $\varnothing$ $12 \mathrm{~mm} \mathrm{Av}=113,097 \mathrm{~mm}^{2}$, Jumlah tulangan 4.

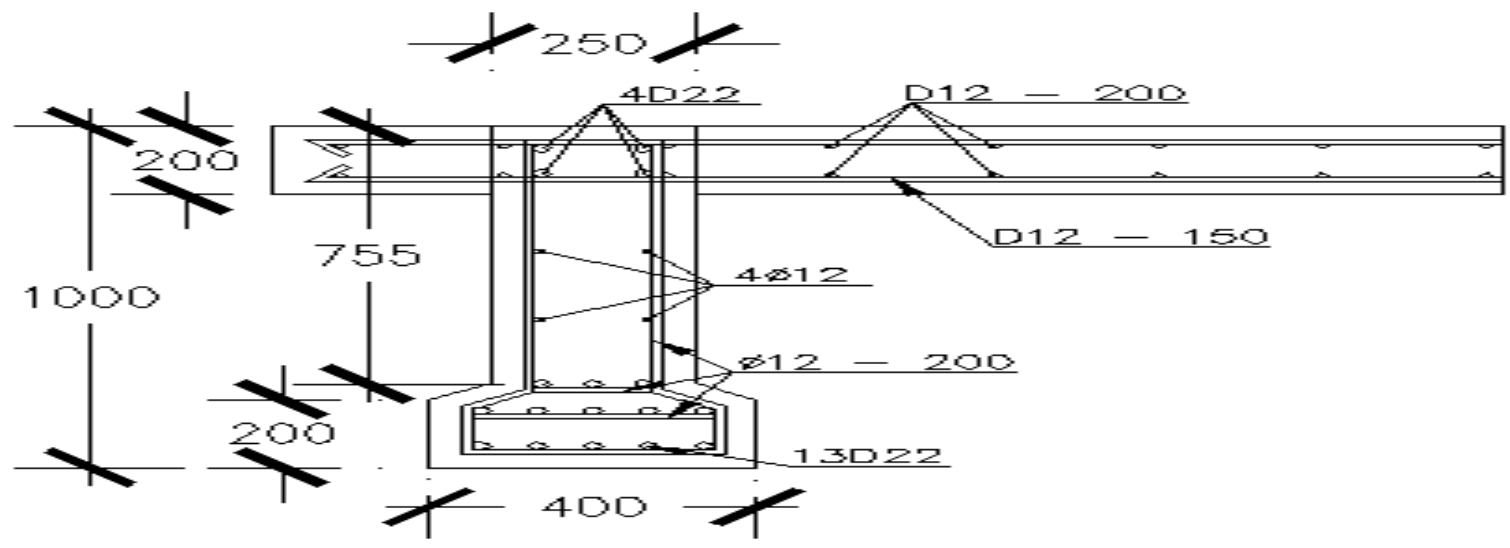

Satuan : Milimeter

Sumber: Analisa Perhitungan (2019)

Gambar 5: Penulangan Balok T Arah Melintang

\section{Balok Diafragma}

Dalam pembebanannya diafragma ini tidak menahan beban luar apapun kecuali berat sendiri balok diafragma tersebut. Data Perencanaan $\mathrm{h}=300 \mathrm{~mm}, \mathrm{~b}=200 \mathrm{~mm}, \mathrm{~L}=1,97 \mathrm{~m}, \mathrm{cc}$ $=40 \mathrm{~mm}, \mathrm{fy}=240 \mathrm{MPa}, \mathrm{f}^{\prime} \mathrm{c}=24,9 \mathrm{MPa}$, Øtulangan $=12 \mathrm{~mm}$, Øsengkang $=8 \mathrm{~mm}, \mathrm{~d}=246$ $\mathrm{mm}$, $\mathrm{qd}=172,8 \mathrm{~kg} / \mathrm{m}$. Perhitungan Tulangan Utama, $\phi$ (faktor reduksi) $=0,8($ RSNI T-122004. pasal 4.5.2), Mmax $=83,827$ kg.m, $M n=1047843$ N.mm, dipakai tulangan $\varnothing 12$ dengan luas penampang $\left(\mathrm{A}=113,1 \mathrm{~mm}^{2}\right.$ ), tulangan yang perlukan 3 batang. Perhitungan Tulangan Geser, $\phi$ (faktor reduksi) $=0,7$ (RSNI T-12-2004. pasal 4.5.2), $\mathrm{Vu}=1702,08 \mathrm{~N}$, dipakai tulangan sengkang yaiut $\varnothing 8 \mathrm{~mm} A v=50,26 \mathrm{~mm}^{2}$, Jarak tulangan geser yang diperlukan $180 \mathrm{~mm}$.

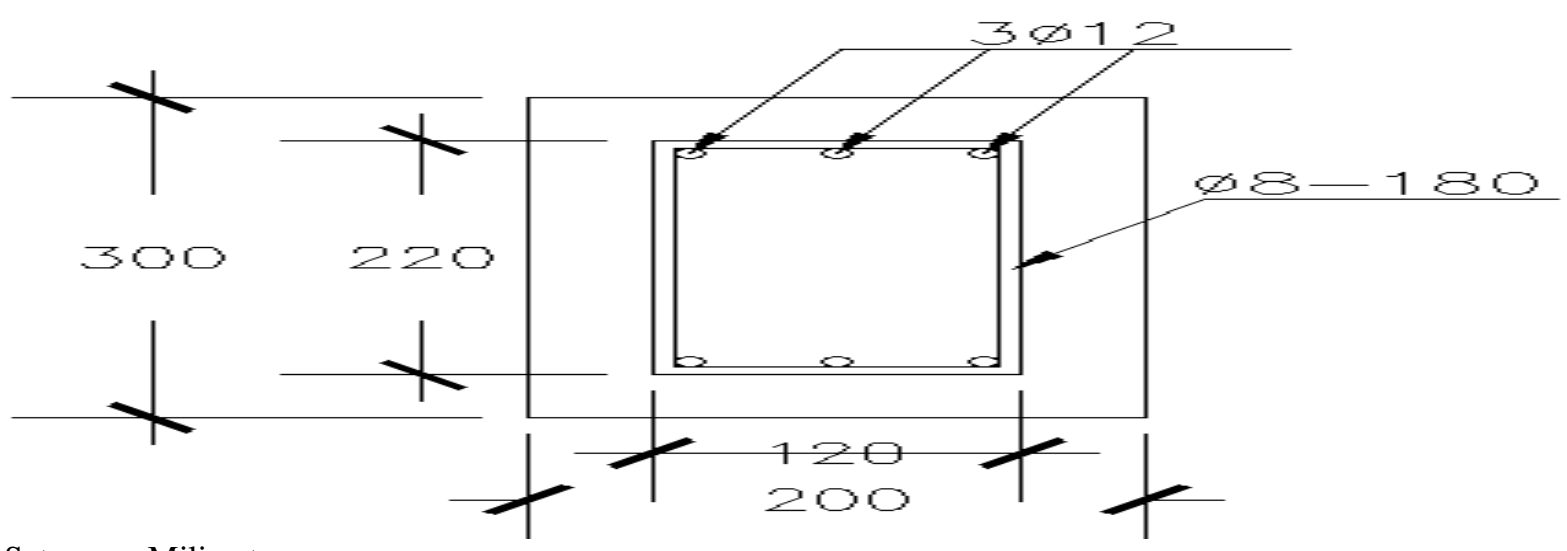

Satuan : Milimeter

Sumber: Analisa Perhitungan (2019)

Gambar 6: Penulangan Diafragma 


\section{Elastomer (Bearing Pad)}

Perletakan direncanakn menggunakan elastomer dengan dimensi 40x60x4,5 cm. Digunakan CPU Elastomeric Bearing tebal $45 \mathrm{~mm}$ isi plat baja $3 \mathrm{~mm}$ dengan kuat tekan $=56$ $\mathrm{kg} / \mathrm{cm}^{2}$ sehingga $30,26 \mathrm{~kg} / \mathrm{cm} 2<56 \mathrm{~kg} / \mathrm{cm}^{2}$.

\section{Perhitungan Daya Dukung Tiang Pancang}

a. Kekuatan bahan tiang

Diameter tiang pancang $=30 \mathrm{~cm}$, tebal beton $=6 \mathrm{~cm}, \mathrm{fc}=29,05 \mathrm{MPa}=\mathrm{K}-350, \sigma ' \mathrm{~b}$ $=29,05 \times 0,33=9,59 \mathrm{MPa}$ (tegangan ijin bahan tiang), A cincin beton tiang $=\left(1 / 4 \pi \mathrm{d}^{2}\right)-$ $\left(1 / 4 \pi(\mathrm{d}-6 \times 2)^{2}=452,39 \mathrm{~cm}^{2}, \mathrm{P}\right.$ tiang $=9,56 \times 10^{1} \times 452,39=43368,3 \mathrm{~kg}$.

b. Perhitungan Daya Dukung Tiang Pancang berdasarkan Data Sondir

Diambil data sondir dengan data sebagai berikut $\mathrm{qc}=150 \mathrm{~kg} / \mathrm{cm}^{2}, \mathrm{JHP}=3729$ $\mathrm{kg} / \mathrm{cm}$, kedalaman $=12,4 \mathrm{~m}, \mathrm{P}$ tiang $=105614,06 \mathrm{~kg}$, daya dukung tiap tiang pada kelompok tiang, $\mathrm{P}_{\text {ult }}=\mathrm{E} \times \mathrm{P}=89142,68 \mathrm{~kg}, \mathrm{P}_{\text {ult }}>\mathrm{P}_{\max }, 89142,68>33548,13 \mathrm{Kg}$.

\section{Penulangan Abutment Trestle Arah Melintang}

Besarnya gaya $\mathrm{P}$ yang diterima 1 tiang pancang $\mathrm{Pmax}=33,55 \mathrm{~T}$. jarak antara beban terluar abutment dengan titik berat pondasi tiang pancang $(\mathrm{x})=0,6 \mathrm{~m}$, Pmax $\mathrm{x} X=20, \mathrm{~h} 13$ t.m,fy $=$ BjTS $30=295 \mathrm{MPa}, \mathrm{fc}=24,9 \mathrm{MPa}=\mathrm{K}-300, \mathrm{~h}=700 \mathrm{~mm}, \mathrm{~b}=1000 \mathrm{~mm}, \mathrm{cc}=40$ $\mathrm{mm}$, D tulangan utama $=22 \mathrm{~mm}, \mathrm{~d}=649 \mathrm{~mm}$

Tulangan Utama, $\phi$ (faktor reduksi) $=0,8$ (RSNI T-12-2004. pasal 4.5.2), $\mathrm{Mn}=$ $25,16 \times 10^{7}$ N.mm, dipakai tulangan $\varnothing 22$ dengan luas penampang $\left(A=380,13 \mathrm{~mm}^{2}\right)$, Jarak tulangan yang diperlukan $120 \mathrm{~mm}$

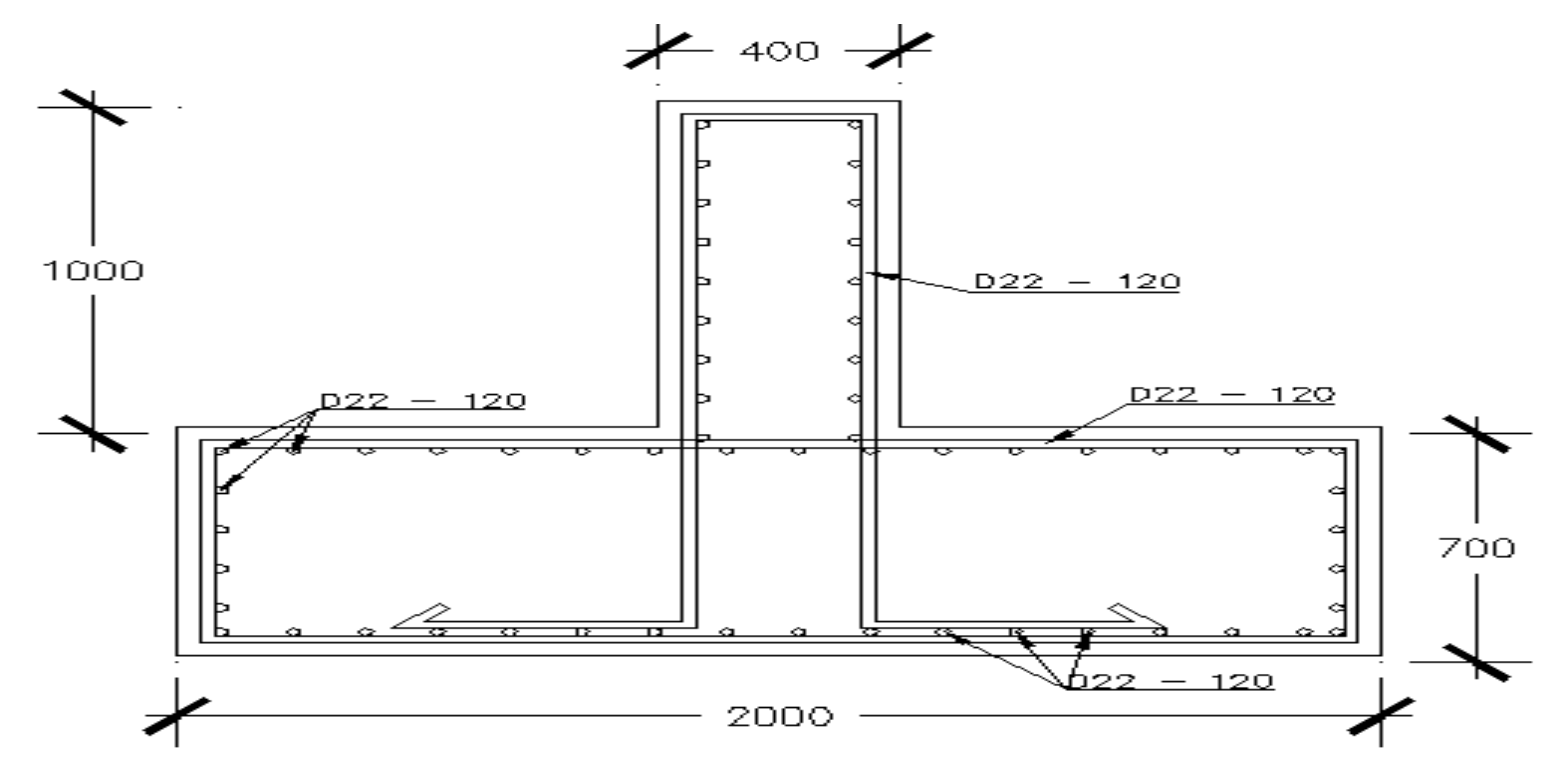

Satuan : Milimeter

Sumber: Analisa Perhitungan (2019)

Gambar 7 : Penulangan Abutment Trestle

\section{SIMPULAN}

Berdasarkan hasil analisis data dan perhitungan dapat disimpulkan Tinggi penampang gelagar memanjang hasil perhitungan lebih besar $(100 \mathrm{~cm})$ dibanding tinggi penampang gelagar existing $(82 \mathrm{~cm})$.

Total luas penampang gelagar memanjang pada setiap bentang hasil perhitungan 0,568 $\mathrm{m}^{2}$ lebih kecil dibanding total luas penampang gelagar existing $0,693 \mathrm{~m}^{2}$. 
Total luas penampang tulangan memanjang pada gelagar memanjang di setiap bentangnya hasil perhitungan 12924,51 mm lebih besar dibanding existing $10254,16 \mathrm{~mm}^{2}$.

Total luas penampang tulangan sengkang gelagar memanjang di setiap bentangnya hasil perhitungan 11535,93 $\mathrm{mm}^{2}$ lebih kecil dibanding existing 19339,64 $\mathrm{mm}^{2}$

Total luas penampang tulangan sengkang balok diafragma di setiap bentangnya hasil perhitungan $2412,743 \mathrm{~mm}^{2}$ lebih kecil dibanding existing $3619,115 \mathrm{~mm}^{2}$.

Total luas penampang tulangan lentur plat lantai di setiap bentangnya hasil perhitungan $15381,24 \mathrm{~mm}^{2}$ lebih besar dibanding existing $12893,1 \mathrm{~mm}^{2}$.

Total luas penampang tulangan arah memanjang abutment trestle di hasil perhitungan $19766,9 \mathrm{~mm}^{2}$ lebih besar dibanding existing $7238,229 \mathrm{~mm}^{2}$.

Total luas penampang tulangan arah melintang abutment trestle di hasil perhitungan $22807,96 \mathrm{~mm}^{2}$ lebih besar dibanding existing 7640,353 $\mathrm{mm}^{2}$.

Total luas penampang tiang pancang pada setiap abutment trestle hasil perhitungan $1809,557 \mathrm{~cm}^{2}$ lebih besar dibanding existing 2714,336 $\mathrm{cm}^{2}$.

Penggunaan tiang pancang menggunakan pancang 12,4 meter dengan diameter $30 \mathrm{~cm}$ dan tidak menggunakan perkuatan pondasi, yang dimana existing pada jembatan ini menggunkan perkuatan pada pondasi.

Pada jembatan ini menggunakan perletakan elastomer berdimensi 40x60x4,5 cm dengan isi plat baja $3 \mathrm{~mm}$, yang dimana existing jembatan ini tidak menggunakan perletakan ( balok gelagar langsung diletakkan pada abutment trestle ).

\section{DAFTAR PUSTAKA}

Asiyanto. 2005. Metode Konstruksi Jembatan Beton. Jakarta: UI-Press.

E, Sutarman. 2013. Konsep dan Aplikasi Pengantar Teknik Sipil. Yogyakarta: CV Andi Offset.

http://id.m.wikipedia.org/wiki/Jembatan. Jembatan.( dikunjungi pada tanggal 9 Januari 2019 pukul 21:30 WIB).

Imran, I. SI-3121 Stuktur Beton I. Bandung: ITB.

Longa, N. 2015. Perencanaan Jembatan Beton Bertulang Balok T SEI Nyahing Kota Sendawar Kutai Barat Kalimatan Timur. Surabaya: Universitas Narotama.

MKB No. 009/BM/2008 Perencanaan Struktur Beton Bertulang Untuk Jembatan. Jakarta: DJBM.

RSNI T-12-2004. Perencanaan Struktur Beton untuk Jembatan. Jakarta: BSN.

SNI 1725-2016. Pembebanan untuk Jembatan. Jakarta: BSN.

SNI 2052-2014 Baja Tulangan Beton. Jakarta: BSN.

SNI 2847-2013 Persyaratakan Beton Struktur Untuk Bangunan Gedung. Jakarta: BSN.

Tharmizi, A. 2009. Kajian Analisa Bangunan Atas Jembatan Beton Bertulang Type Trapesium Sungai Idung Idup Dengan Panjang Bentang 20 Meter. Jambi: Universitas Batanghari. 